\title{
EXPONER A LOS VENCIDOS: MEMORIA, TRANSMEDIA Y EMANCIPACIÓN ${ }^{1}$
}

\begin{abstract}
Antonio ALÍAS
Universidad de Granada antonioalias@ugr.es

$\mathrm{E}$ 1 proyecto político redentor del Walter Benjamin, reconoce Martin Jay, «ya no puede generar mucho entusiasmo» (2001: 14). En la afirmación del historiador americano, sin embargo, parecen resonar los ecos de aquel discurso - entonces contemporáneo- de Francis Fukuyama que proclamaba en su conocido ensayo «The End of History?» (1989) la eclosión de las democracias liberales, tras el desmoronamiento de los regímenes comunistas en Europa del Este. El triunfalismo con el que Fukuyama trata la victoria del liberalismo como sistema político y económico, no obstante, contenía una lectura implícita que trasciende a la historia política - como si de un cierre en falso se tratase: «the end point of makind's ideological evolution and the final form of human government» (2006: 6) ${ }^{2}$ — para señalar los modos de vida que, en torno al capitalismo, se imponían ya en las sociedades consideradas occidentales. O, si se prefiere, por vía negativa: el fin de la historia era, realidad, el fin de un relato político, el de una ideología sostenida en el ejercicio de la revolución: el comunismo. Las afirmaciones de Fukuyama, a pesar de querer confirmar el agotamiento de la enconada dialéctica entre comunismo y capitalismo durante los años de la Guerra Fría, ciertamente promueven su fin para establecer así un nuevo discurso histórico - académico- sobre un orden mundial liberal, que contemporáneamente critica, no ya un sistema político fundado en viejas ideas marxistas, sino a una ideología que como esta descendió hasta un paroxismo de violencia ideológica (Fukuyam, 1989) y, por tanto, contraria a los ideales de consenso de la socialdemoracia. De alguna manera, la capitulación de lo revolucionario aquí está vinculado a la falta de potencialidad política con la que Jay invalida, precisamente, las ideas de Benjamin. Si el pensador alemán ya no genera entusiasmo, según sus palabras, es porque el historiador americano identifica su pensamiento con la

\footnotetext{
${ }^{1}$ Este artículo se enmarca dentro del proyecto Narrativas transmediales: nuevos modos de ficción audiovisual, comunicación periodística y performance en la era digital (Referencia CSO2013-47288-P), dirigido por el profesor Domingo Sánchez-Mesa Martínez. Ministerio de Economía y Competitividad.

${ }^{2}$ Afirmaciones que el propio autor, Francis Fukuyama, recoge de nuevo en la introducción de la revisión sobre aquel ensayo de 1989 y que supone la escritura de su ya clásico The End of History and the Last Man, New York, Free Press, (1992) 2006.
} 
disolución de los símbolos políticos del marxismo - pues suponemos que se alude aquí a ese final de la historia: el desmoronamiento del bloque soviético y a la reunificación de la RFA con su homóloga democrática一, pero también a la aparición de nuevas corrientes de pensamiento desde la izquierda que, sobre los aspectos de una historia en continua reificación, hacen difícil una lectura política donde ideológicamente se ubique a Benjamin. Pues frente a la esperanza de un nuevo tiempo - futuro- sin historia con la que Fukuyama indica en sus primeros trabajos —en contraposición a la frustrada historia de un siglo XX tramada en crisis y conflictos, cuando las expectativas de progreso eran grandes (2006: 5)—, el pensador alemán es instalado en una melancolía de izquierdas cuyos ideales revolucionarios quedan, políticamente, en punto muerto por la probada inoperancia de un socialismo real en el mundo, según esta lectura. Pero este asunto no ha sido siempre bien entendido por parte de la crítica y gran culpa de ello tiene que ver con hacer de Walter Benjamin un presupuesto exclusivo de la praxis política marxista - y del supuesto fracaso político, una ruina ideológica-, cuando de esta se extrae, precisamente, la peculiaridad del pensador berlinés, no ya frente a la historia o el capitalismo, sino de su extraña posición dentro del pensamiento marxista.

Así es como Bolívar Echevarría entiende las Thesen Über den Begriff der Geschichte [Tesis sobre el concepto de la historia] de Benjamin: como «una crítica los fundamentos teóricos del discurso comunista o socialista teniendo en cuenta como elemento de referencia la versión oficial del mismo [...] lo que se conoció como teoría o marxismo de la socialdemocracia». Es decir, Benjamin habría asumido una labor teórica de un proyecto político fracasado — el marxismo-, continúa Echevarría, que alcanzara discurso verdaderamente histórico, ciertamente materialista, un «discurso revolucionario adecuado a la época del ocaso de la modernidad» ${ }^{3}$. La empresa de llevar lo teórico a un fin político, si en ella se quiere ver el gesto revolucionario del pensador alemán, depende de una asunción mesiánica de la historia que, sin embargo, no ha sido fácilmente entendida por su heterodoxia en un pensamiento que, en ocasiones, ha visto enrocadas sus posibilidades políticas en una mala adecuación de sus ideas y planteamientos teóricos bajo el dogma. De ahí que, continua Jay, «el consecuente llamado que hace Benjamin a favor de una nueva versión mesiánica de la historia universal ha tenido mucho menos éxito», pero matiza, «aun cuando el impulso redentor [...] ya no me inspira confianza, la idea general de Benjamin sobre la tensa interacción existente entre el pasado y el presente, aún debe imponer respeto». Las palabras de Jay demuestran, al menos académicamente, la resistencia de lo que en el pensamiento del berlinés resulta singular, es decir, la aceptación de un mesianismo revolucionario. Lo heterodoxo de los planteamientos de aquél, entre la mística judía mesiánica y la aspiración revolucionaria romántica contra la filosofía del progreso histórico, marcan a su vez una disidencia respecto al pensamiento político de izquierdas, pero también respecto a la ortodoxia religiosa (Löwy,

\footnotetext{
${ }^{3}$ No sólo el contenido de las Tesis benjaminianas, sino también la forma de su exposición participaban de la ya conocida expresión organizar el pesimismo, que aunque contenía un lamento por el mundo modernamente desencantado, realmente su melancolía alude a esa preocupación que, sin embargo, conlleva siempre una responsabilidad última por transformarlo. Benjamin, Walter, Tesis sobre la Historia y otros fragmentos (introducción y traducción de Bolívar Echeverría). En: http://www.bolivare.unam.mx (última consulta, 16-07-2017). De esta edición se ha consultado la introducción a cargo de Bolívar Echevarría, puesto que la edición consultada de las Tesis sobre el concepto de la historia para el resto del artículo pertenece a Abada (2012).
} 
2010: 8-25), algo que no será tampoco comprendido en el ámbito de la filosofía actual, contraria a asumir el residuo escatológico en el pensamiento del berlinés ${ }^{4}$.

Aún así, si el poco entusiasmo tuviera que ver con un fin histórico, con su signo político, nada más propicio que un pensamiento como el de Walter Benjamin para afrontar los cambios en un resurgir de la historia. Podríamos perfectamente hacer ostensible la vigencia de un Walter Benjamin revolucionario y mesiánico sobre los profundos cambios históricos, sociales y políticos de la última década del siglo XX, precisamente por la concomitancia con los sucesos que llevaron al pensador a escribir su obra y, sin embargo, no sucede salvo excepciones. La más significativa de estas es la de Daniel Bensaïd. En las antípodas de las palabras de Jay, Bensaïd justifica al filósofo en su obra Walter Benjamin, sentinelle messianique (1990) en un momento político crítico con los cambios históricos que se estaban sucediendo entonces y en la cual su exégesis descubre un Benjamin plenamente político, pero como bien explica en su introducción Enzo Traverso (Bensaïd, 2010: 8), no sobre el filósofo berlinés, sino en diálogo con él. De esta manera, sabemos que lo que hace de manera muy peculiar Bensaïd no es la lectura de un experto sobre Benjamin, sino una actualización de su pensamiento que, ahora a través del propio Bensaïd, se asume necesario para poder afrontar los acontecimientos ya antes señalados, entre los cuales la historia del comunismo y la tradición marxista caen en descrédito. Estas dudas políticas, donde según el francés se deben repensar las nuevas vías de un proyecto emancipador, no pueden estar separadas de una «forme messianique comme promesse d'une redemption à venir» (Bensaïd, 2010: 11) fiel a la promesa de los perdedores y, sobre todo, en una inteligente comprensión de estos cambios históricos como interrupción del curso de historia. La reflexión de Bensaïd, no obstante, marca de nuevo este fracaso de las políticas marxistas como ya indicaba Echevarría o Jay, pero con la justa melancolía del que en un momento de inestabilidad política, espera la mayor de las respuestas emancipatorias: la posibilidad de revertir la historia. Pero como sucede en todo momento de crisis, el instante de peligro surge bajo la proliferación del liberalismo que para Bensaïd sólo se combate desde la actualización de la revolución mesiánica benjaminiana (Bensaïd, 2010: 12).

Este momento de la crítica francesa debemos entenderlo en el marco de nuestro artículo como una de las actualizaciones más importantes y radicales por cuanto tiene de rescate de pensamiento de Walter Benjamin y, también, por ser considerada una atrevida invitación a repensar la revolución como acto de renovación política que, de alguna manera, se han inmiscuido en discursos divergentes sobre las actuales políticas de memoria desarrolladas en varias de las democracias europeas para la reconciliación social tras un pasado civil convulso. Por lo tanto, para el pensador francés como para el alemán, el marxismo, que era la revolución posible a partir de un sujeto histórico y social oprimido, y el mesianismo, como el necesario advenimiento de un nuevo tiempo histórico, son indisociables. Si el

\footnotetext{
${ }^{4}$ En su lectura sobre la continua actualidad de Walter Benjamin, Martin Kohan se refiere, contrariamente, a una presencia inactual del pensamiento benjaminiano frente al uso fetichizante de la teoría y de la crítica contemporáneas: «leer siempre desde otro lado, siempre desde la tradición o desde otro horizonte [...] leer siempre desde otros tiempos» en su propio tiempo (2013: 204). De ahí lo paradójico o inactual de, entre otras ideas - y para lo que aquí nos interesa一, la de ofrecer una promesa de redención para los vencidos de la historia. Aunque en Benjamin los vencidos refieren a las víctimas del progreso histórico, es decir, a los muertos por los conflictos de la historia, su reivindicación mesiánica actúa a modo de recuerdo, de presencia significativa, de memoria epistémica.
} 
marxismo había fracasado políticamente una vez más, solo mediante una transformación teórica sobre el concepto de historia podrá mantener su continuidad a lo largo de la historia, esta vez pensada contemplando el pasado fracasado como memoria.

\section{La tradición de los oprimidos y el olvido de los vencidos}

Sin embargo, a pesar de la ingente crítica aparecida en los últimos años alrededor de Benjamin, las actualizaciones de su pensamiento y de sus conceptos se resisten a recorrer hoy otras vías que no sean exclusivamente estéticas. Bensaïd trae en su replanteamiento sobre el pensador berlinés el concepto de memoria convertido, ahora en términos del francés, en una «mémoire des vaincus» [«memoria de los vencidos»] (2010: 13), que será un lectura muy depurada ya del Eingedenken [«rememoración»] benjaminiano. En la denominación adquiere evidencia uno de los rasgos de la memoria que fue expresada como crítica al concepto de la historia, en concreto, en la tesis número VIII, donde Benjamin se refiere, en realidad, a la «tradición de los oprimidos» supeditada a «ese enemigo que no ha cesado de vencer» (2012: 171-172). El desplazamiento del adjetivo oprimidos al de vencidos, señala, no obstante, una oposición más clara con la figura del vencedor — que sí aparece mejor delimitada en las Tesis-, aunque lo que nos indica es la nueva ubicación del concepto como fundador de un discurso vinculado a los ahora estados democráticos con un pasado conflictivo reciente. Nos referimos aquí a la denominada Razón de los vencidos que el propio Mate funda desde las ideas benjaminianas por ser «tan conscientes del lugar en la moral y en la política de la víctima y del verdugo, que no se puede despreciar a la memoria en nombre de la historia porque la memoria no es un sentimiento, sino una forma irreductible de conocimiento» (2008: 6). En estas palabras se constata la línea que atraviesa el trabajo de investigación del filósofo español, en donde el concepto de memoria ha ido actualizándose determinado por las circunstancias discursivas en las que ha recalado, no exento, claro está, de las condiciones que lo predeterminan como forma de conocimiento. Y en su devenir una lucha particular, la de ese elemento mesiánico que permanece inscrito en la memoria benjaminiana y que, a pesar de todo, se mantiene porque de él depende su distinción frente a otras concepciones de memoria. Hasta alcanzar un estatus cultural, la memoria ha pasado por momentos críticos, como aquel intento de secularización por parte de la Teoría crítica, el importante momento crítico en las actualizaciones de Adorno, pero también ha transitado por otro tipo de momentos como son los olvidos políticos y los silencios críticos infringidos, por ejemplo, por Habermas. De esta parte política podemos dar cuenta de manera peculiar de la transición que el concepto de memoria tendrá en España, donde aparte de la transición teórica, la política se asume como criba hacia la democracia y la domesticación final de cualquier atisbo revolucionario o dialéctico contenido en el concepto de memoria heredado de Walter Benjamin ${ }^{5}$.

\footnotetext{
5 Reyes Mate se refiere a la «despolitización de la política» que en los procesos democráticos normaliza cualquier dimensión conflictiva de la política (2003: 111). En el caso del concepto de memoria proveniente del pensamiento de la Teoría crítica acontece esto mismo. El reconocimiento, en primer lugar, de su lectura mesiánica, pero, sobre todo, su carácter dialéctico - Adorno y Metz- y subversivo - Marcuse- hacen de él un concepto poco adecuado para una
} 
Si somos capaces de distinguir la recepción de la obra de Walter Benjamin de la actualización de su pensamiento - puesto que no van necesariamente unidas-, podemos observar en el caso concreto de España una singularidad conceptual. Hasta 1972 no llegan las ideas del filósofo alemán a manos de Jesús Aguirre —que previamente a su introducción, habían sido traducidas al español por el escritor y ensayista argentino Héctor A. Murena-, con lo cual no podemos hablar de un acceso cultural ni de divulgación de su pensamiento durante la época más dura del franquismo. Este dato resulta altamente simbólico para la introducción del pensamiento benjaminiano en España, si bien es cierto que el pensamiento crítico - lo que en el ámbito filosófico se denomina Teoría crítica - ya se había iniciado en el ámbito académico español desde 1962 con las primeras traducciones de Adorno ${ }^{6}$. Sin embargo, hemos de concretar que la introducción de Benjamin como momento inaugural de una idea de memoria es un largo proceso intelectual y político. Sobre la pista nos pone el excelente trabajo sobre la filosofía española en los últimos años del franquismo y después de la Transición (Vázquez García, 2009). El entramado filosófico que se empezaba a trabar en los núcleos académicos españoles estaba vinculado a una importante intelectualidad teológica y a otras agrupaciones religiosas, como es el caso de la Compañía de Jesús. Decíamos antes que la traducción de Jesús Aguirre resulta primordial puesto que, además de ser el introductor de la obra de Nietzsche en España, desde la década de los años sesenta estuvo al frente de la editorial Taurus (Vázquez García, 2009: 196), en torno a la cual se reúnen grupos vinculados a los sectores progresistas la Iglesia Católica. Entre ellos cabe destacar Reyes Mate o Javier Muguerza, que comparte con Aguirre un ciclo de conferencias sobre la escuela de Frankfurt en el curso de 1970. Nada de esto tendría cabida en el presente artículo si no apuntara a las siguientes circunstancias añadidas: la primera es la que vincula a Reyes Mate con Metz, de quien fue discípulo en Münster durante su formación en teología; en segundo lugar su posterior entrada a la dirección del CSIC, una vez que el Opus Dei hubiera desistido de su dirección.

La actualización de Benjamín en España, así como su verdadera recepción, tiene que ver con el contacto directo entre Metz y Mate (Vázquez García, 2009: 192-193). De hecho, la atención del español sobre la memoria, viene de la importancia que el teólogo alemán otorga a su concepción filosófica, más allá de la exigencia conceptual que la teología tiene sobre ella. Desde luego la concepción de la memoria queda filtrada de Benjamin por Metz — si bien es cierto, debidamente entrelazada con la memoria considerada como crítica de Adorno- se centrará en el supuesto del

normalización legislativa. Sin embargo, los valores del concepto de memoria filtrado por la intelligentsia española acabarán por formar parte del sentido de la necesidad de una memoria como justicia de facto.

${ }^{6}$ Sobre la recepción de la Teoría crítica en España resultan fundamentales los artículos de Sergio Sevilla «La recepción en España de la Teoría crítica» (2010) y en una línea muy similar el trabajo de Vicente Gómez titulado «Teoría Crítica en España. Aspectos de una recepción» (2009). En ambos se da cuenta de la entrada del pensamiento crítico —-también conocido como Teoría crítica o Escuela de Frankfurt - en la España de la dictadura franquista a partir de instituciones universitarias y grupos de pensamiento a ellas adheridos. Sin embargo, como dice su autor, «La Teoría Crítica no aparece entre nosotros como llovida del cielo. Su recepción inicial permanece indisolublemente ligada a los tempranos intentos llevados a cabo en nuestro país por introducir el marxismo, el paradigma histórico-filosófico en el que naturalmente cabe situarla» (Gómez, 2009: 4). Por tanto, en un sentido casi más político que un auxilio epistémico. La actualización del concepto de memoria de Walter Benjamin tendrá que ver, de manera clara, con la introducción de esta lectura marxista. Para una lectura más profunda, consúltese en bibliografía ambos artículos. 
sufrimiento como autoridad de conocimiento que Mate traducirá después en términos de compasión o conciencia empatizadora (2008: 208) y en los cuales se evoca a la memoria passionis del teólogo alemán. Estamos, pues, ante una actualización del débil concepto de memoria mesiánica de Benjamin que, sin embargo, entra con fuerza en el pensamiento español como parte de un relato marxista en la política de izquierda clandestina al final del franquismo. De ahí que la razón anamnética de Metz es ahora una razón concreta, es decir, directamente pensada sobre el olvido de las víctimas de la Guerra Civil española, de todos los vencidos.

Todos esto rasgos hacen inconfundible el discurso de memoria pensado por la tradición de la Teoría crítica y, sin embargo, con la llegada de la Transición democrática este modelo no llega a ser legitimado (Mate, 2008: 218) para formar parte, entonces, de la primera ley de un parlamento ya constituido democráticamente, la ley 46/1977 — Ley de la amnistía —, que finalmente no acaba por cuestionar al franquismo ni tampoco a reivindicación alguna de los ideales democráticos que valían como credencial. Contrariamente, dice Rafael Escudero, «estas medidas declaraban expresamente estar basadas en el espíritu de perdón, concordia y reconciliación iniciado ya en los años cuarenta. Heredan el discurso y son una buena muestra del principio de equidistancia propio de la Transición» (Rafael Escudero, 2013: 13). Este discurso corresponde al proceso de democratización iniciado tras la muerte del dictador Francisco Franco y estuvo presidido por el así denominado consenso de la transición, según el cual partes de la representaciones provenientes del franquismo y de la oposición antifranquista sellaron «un pacto de olvido sobre el pasado dictatorial» (2013: 9) definido a partir de tres elementos: amnesia, amnistía y equidistancia. En una lectura comparatista que podría ser innecesaria, empero ilustradora, este proceso político se puede asociar al relato de la recuperación alemana — también denominado Wirtschaftswunder, es decir, milagro económico-, precisamente, por su carácter amnésico en vista de una pronta recuperación del país. Tanto en un proceso como el otro se impidió una normal comprensión de los acontecimientos del pasado y, más grave aún, se ocultaron violaciones a los derechos humanos cometidos de igual manera por el nacionalsocialismo y durante la dictadura franquista.

\section{De la amnesia sobre el pasado al derecho de memoria: recuerdo, deber y justicia}

Aproximarse a la Transición es, más allá de la reconciliación sobre los gestos políticos y los acuerdos históricos, una cuestión de memoria, sobre todo después la aprobación de la Ley 52/2007, más conocida como Ley de Memoria Histórica. En este sentido la justicia se asume, significativamente, como el último tramo para el reconocimiento político de un relato, la memoria, que aún hoy no se contempla en su totalidad desde las funciones constitucionales del estado español. En esta precariedad tienen que ver, por una parte, la falta de normativa de la propia ley sobre las fosas comunes y, por otro, con un desconocimiento epistemológico de las ideas y conceptos en los que este joven relato democrático de la memoria española se fundamenta. Porque desde la Transición hasta ahora hemos visto el devenir político de una reivindicación en un derecho propio a recordar, pero poco se ha 
contado que durante este trayecto otro relato ha ejercido, correlativamente, de instancia crítica y teórica. Se trata, pues, de vislumbrar en este apartado esa otra transición en la que no estuvo en juego tanto la suerte democrática del país, como la legitimación de una línea de pensamiento - como hemos ido advirtiendo a lo largo del trabajo del artículo- de procedencia alemana: la Eingedenken [recordación o rememoración] destilada de las obras de pensadores como Walter Benjamin, Th. W. Adorno y Max Horkheimer, que se fraguó en los centros académicos y revistas de filosofía durante los últimos años de la dictadura franquista. Así, en la emancipación intelectual de España durante la Transición tuvo cabida una lectura de la filosofía judeoalemana que, como hemos visto, no sólo sirvió para la recuperación y apropiación ajena de la figura de Walter Benjamin —en su marxismo heterodoxo-, sino también para el emprendimiento ético, moral y conceptual de un pensamiento sobre la memoria que no encontraba lugar en la hegemónica filosofía oficial del franquismo.

Reflexionar desde una actualidad en la que sociedad de la memoria ha subsumido, de alguna manera, el potencial emancipador con el que el teólogo J. B. Metz quiso dotar a la memoria, al convertirla en «el concepto más indispensable de una filosofía» contemporánea, es entender la escritura teórica bajo el primado del devenir práctico de la razón, esto es, como un ejercicio de libertad (Metz, 1999: 2-3). Así pues, la cultura de la memoria desde la cual este pretendió medir todos los acontecimientos de la historia, siempre bajo el recuerdo imborrable del desastre humano del Holocausto judío y demás catástrofes ocurridas alrededor de la Segunda Guerra Mundial, sin embargo ha ido perdiendo fuelle. Esto se sucede cuando, contradictoriamente, esa urgencia de memoria ha pasado a ser relato recurrente en un presente encerrado entre la incertidumbre sobre el pasado —nunca del todo conocido- y el futuro que tampoco lo asegurará en la historia. En este impasse la memoria ha calado, más allá de las lecturas nostálgicas y de la recuperación entendida como objeto de los estudios culturales, en el mismo proceso de democratización desarrollado por muchos estados que tienen como protagonista de su historia conflictos civiles fundamentados en la violencia política, y que acuden a ella, a la memoria, convencidos de su capacidad conciliadora e integradora. Y aquí es donde el derecho surge como instrumento de representación, más aún, de reparación del pasado, marca significativa de la transición de lo teórico a la praxis o, si se prefiere, de un discurso filosófico a una ejercicio de política democrática. Así es como la memoria ha devenido en políticas estatales amparadas en los principios fundamentales de los Derechos Humanos o, lo que es igual, de aquella fuerza emancipadora que señalara Metz a un dictamen político que parece cumplirla en su ejecución. Entre uno y otro aquellos parámetros con los que Metz trataba de dar sentido a la historia, han acabado por ceder ante las estrategias propias del consumo imperante en nuestra sociedad, y es la memoria ahora más que nunca en su provecho - como bien lo han sabido ver Ricoeur (2000), Todorov (2004) o Traverso (2007) - donde se define un nuevo topos para los excesos de la política. Así es como la memoria funciona, propiamente reducida a una cuestión de usos y abusos. No son de extrañar los signos de agotamiento en torno a esta cuestión detectada por muchos de los teóricos especializados en memoria. Uno de ellos es Andreas Huyssen (2002), según el cual el interés por el pasado en la que esta, así denominada, cultura de la memoria se fundamenta, se ha tornado en una extrema fijación por su 
Exponer a los vencidos: memoria, transmedia y emancipación

recuerdo conmemorativo en memoriales y museos, por lo que la reciente e imparable tendencia inflacionista de la memoria implicada en esa dinámica ha generado numerosos análisis, la mayoría de los cuales son sólo parcialmente satisfactorios cuando no directamente insuficientes.

En este contexto escogemos como punto de partida tan sólo un par de párrafos de la Ley 52/2007 de 26 de diciembre, no con la idea de analizar críticamente su fundamentación y la querella alrededor de su elaboración, sino entendiéndola como una producción política de esta sociedad de memoria que aquí hemos esbozado, y en las que el propio sentido del concepto queda desvirtuado o despolitizado, por usar los términos de Reyes Mate (2008: 208), en el utilitarismo exacerbado en el que ha desembocado la lectura sobre la praxis emancipatoria de la memoria con la que Metz quiso dar continuidad y presencia a las ideas de Walter Benjamin. De alguna manera, también nos serviremos conscientemente de una memoria hecha ley para contraponerla a una categoría de memoria denominada, así, crítica desde presupuestos éticos y políticos, donde algunos de los autores más importantes del pensamiento crítico frankfurtiano extrajeron, precisamente, un sentido de justicia que disentiría prácticamente de su articulación jurídica. La comparación es, si se quiere entender así, no obstante —y en sí mismaun intento metodológico anamnético (Mate, 2013: 15) para repensar temas que tienen que ver con la memoria, o mejor dicho, con ciertas teorizaciones sobre la pertinencia del recuerdo como elemento crítico ante las patologías sociales e históricas, y su devenir hacia unas prácticas políticas.

Dicho esto, pues, entre el quinto y sexto párrafo de la Ley 52/2007 de 26 de diciembre, se establece lo siguiente:

Es la hora, así, de que la democracia española y las generaciones vivas que hoy disfrutan de ella honren y recuperen para siempre a todos los que directamente padecieron las injusticias y agravios producidos, por unos y otros motivos políticos o ideológicos o de creencias religiosas, en aquellos dolorosos períodos de nuestra historia. Desde luego, a quienes perdieron la vida. Con ellos, a sus familias. También a quienes perdieron su libertad, al padecer prisión, deportación, confiscación de sus bienes, trabajos forzosos o internamientos en campos de concentración dentro o fuera de nuestras fronteras. También, en fin, a quienes perdieron la patria al ser empujados a un largo, desgarrador y, en tantos casos, irreversible exilio. Y, por último, a quienes en distintos momentos lucharon por la defensa de los valores democráticos [...] En este sentido, la Ley sienta las bases para que los poderes públicos lleven a cabo políticas públicas dirigidas al conocimiento de nuestra historia y al fomento de la memoria democrática. ${ }^{7}$

De una primera lectura se pueden extraer, al menos, dos ideas de memoria condensadas en sus últimas líneas: una pertenecería al Walter Benjamin de Tesis sobre el concepto de historia —en ese conocimiento de nuestra historia - y, la otra, al Adorno maduro - si leemos el fomento de la memoria democrática en aproximación al deber de memoria adorniano-, pero tanto la una como la otra ya formaban parte de los principios con los que ambos pensadores replantearon — con sus matices uno y otro- una nueva teoría del conocimiento y un orden político desde el materialismo histórico basados en la experiencia sufriente del sujeto. La inversión sobre los condicionamientos para el conocimiento de la verdad desde la experiencia dañada —dirá Adorno: «dejar hablar al sufrimiento es condición de toda verdad»-, es atender a una condición que la razón ha declarado insignificante, según palabras de Reyes Mate, pero sin la cual «no habrá derecho, ni moral, ni política que valga al margen de ella»

\footnotetext{
${ }^{7}$ BOE núm. 310. 22296. La cursiva es nuestra (A. A.)
} 
(2003: 251-259). No contar con esta experiencia, por tanto, sería la injusticia a la que la justicia habría de responder y el lugar donde la memoria adquiere su carácter cognitivo. Sin embargo, y aunque esta idea aparece contemplada en el párrafo antes citado de la ley, hay dos detalles en su contenido que muestran un principio de ocultación que irían, propiamente, contra el deber de memoria con el que se fundamenta; sin referirme, claro está, a la propia denominación de la ley, donde nunca aparece el término memoria.

Antes está el problema del deber de la memoria, pues el aprovechamiento del imperativo categórico con el que Adorno abordó la última parte de su obra Dialéctica negativa - también en el artículo «La educación después de Auschwitz»—, ha acabado por constituirse en un modelo canónico de jurisprudencia sobre los conflictos civiles y las dictaduras militares basadas en la represión clandestina y desapariciones sistemáticas, como también ocurre en algunas de las políticas reparadoras, como es el caso de Argentina. Fue allí, en las páginas de un texto teórico dedicadas a la cuestión del papel de la filosofía tras lo ocurrido Auschwitz, donde el pensador alemán propone una especie de ley moral para los supervivientes de la catástrofe con la que orientar el pensamiento y la acción de los seres humanos, «de modo que Auschwitz no se repita, que no vuelva a ocurrir nada semejante» (Adorno, 2008: 365). Este imperativo fundamental e incondicional, pues de él dependerá la inmediata supervivencia de la humanidad, partía, realmente, de una crítica al imperativo categórico kantiano - una norma abstracta y meramente formal-, del que Adorno dispuso, contrariamente, como una exigencia en la historia desde la experiencia humana y no en la elevación normativa de la legislación. Y con este gesto profundamente moral y comprometido, el pensador alemán pretendió movilizar la memoria de las esperanzas incumplidas y de las injusticias pendientes desde el hábito de la memoria que, como advierte José Antonio Zamora, «impone una mirada agudizada a las catástrofes del presente, implacablemente crítica con sus causas y solidariamente compasiva con sus víctimas» (Zamora, 2004).

Precisamente la crítica que propone Zamora - y volvemos, así, a los dos detalles pendientesno permanece viva en el texto jurídico, al menos conceptualmente. El primero de ellos recae sobre la implícita referencia a las víctimas, puesto que en el texto aparecen eufemísticamente referidas como $a$ quienes perdieron la vida, y el segundo a la ausencia de facto del concepto de memoria histórica en favor de una memoria democrática, que Rafael Escudero detecta ya en el debate conceptual previo a la conformación del texto de la ley y en el cual se habría señalado la preferencia, por parte de la intelligentsia del PSOE, por un acuerdo que respetara los términos del marco legitimador del sistema constitucional alcanzados en la Transición (Escudero, 2013: 37-39). Parte de esta opacidad heredada desde entonces tapaba la procedencia crítica del concepto benjaminiano de memoria — que, según Francisco Vázquez García, fue filtrado por Reyes Mate en su contacto con el pensamiento de la neuen Politischen Theologie durante sus años de formación en Münster, Alemania, como antes hemos referido-, lo que traía aparejado, en cierto sentido, otra transición, en este caso conceptual y en la que, sin embargo, no llega a participar políticamente. Las razones del rechazo a una categoría como la memoria histórica durante la Transición —además de los prejuicios que sobre ella recaen como fuente 
histórica poco fiable y, sobre todo, manipulable-, se debió a que, a partir de ella, se obtendrían suficientes elementos para cuestionar el discurso hegemónico de la equidistancia que, como viene a resumir Escudero, justificaría la reconciliación entre los dos bandos, pues en ambos se ejerció por igual la violencia política. Una equiparación como ésta no podría contar con una justificación benjaminiana, ya que en su concepción de la memoria en tanto recuperación y conocimiento de un pasado que permanecido al margen de la historia oficial $-\mathrm{o}$, incluso, ocultado como ocurrió en los años del franquismo-; una represión ostentada desde el poder autolegitimado que, por tanto, no podría aceptarse en aras del restablecimiento democrático. La crítica epistemológica, entonces, se entremezcla con la actividad política en lo que realmente es un proceso de pérdida del estatus crítico -y no sólo- de la categoría de memoria, cuando, en este sentido, la justicia se asume, significativamente, como el último tramo para el reconocimiento político de un relato, la memoria, que aún hoy no se contempla en su totalidad desde las funciones constitucionales del estado español, en parte debido a esta recepción desvirtuada de las ideas de los pensadores de la tradición crítica de Frankfurt. Porque desde la Transición hasta ahora hemos constatado el devenir político de una reivindicación sobre el derecho propio a recordar, pero poco se ha contado que durante este trayecto otro relato ha ejercido, correlativamente, de instancia crítica y teórica desde el margen académico, como es el discurso de la memoria de los vencidos, desarrollado desde los años ochenta por Reyes Mate en su obra filosófica.

Observar estos desplazamientos para entender desde sus teorizaciones originales hasta sus postulados más recientes, muestra el reconocimiento progresivo de una memoria de la experiencia de sufrimiento social en una norma política e institucional; una memoria esta última incompleta que deja de lado, no sólo su desafío epistemológico por conocer toda la verdad, sino también el político por trastocar el proyecto emancipador que la memoria de Benjamin contiene respecto a las necesidades coercitivas de la ley ante este asunto. Entonces, ¿qué entendía Benjamin por justicia y qué relación guarda esta con la memoria? En su muy comentadas Tesis sobre el concepto de la historia, pero de manera más explícita en su artículo «Notas para un trabajo sobre la categoría de justicia» ${ }^{8}$, aclara que esta no se corresponde con ninguna acción, sino con un estado que afecta a la realidad que ha sufrido una profunda alteración. Es más, en su conocido trabajo «Hacia la crítica de la violencia», ya se había prefigurado una «relación de la violencia con el derecho y la justicia» (Benjamin, 2010: 183). Tiene más que ver, de hecho, con la captación y construcción de la realidad, es decir, que el sentido la justicia benjaminiana pertenece a un orden epistémico. Es así como si con la restitución y la reorganización de esa realidad, se tratara de encontrar el lugar de cada cual en la constitución del mundo, de ahí la necesidad de visibilizar lo que ha sido ocultado en la construcción fática de la historia. Dicha visibilización de los oprimidos, de los desaparecidos o de los sin-nombre, como señala Reyes Mate, es asumida como un proceso necesario desde el trabajo de la memoria. Porque es propiamente ella una herramienta sobre el olvido y no sólo eso; es además la memoria una historia passionis (Metz; Reyes Mate), donde todas esas zonas patéticas y oscuras adonde el concepto no alcanza, potencian las utopías

${ }^{8}$ Cfr. De la Garza, Ma Teresa (2002: 135-136). 
no realizadas: los proyectos de vida frustrados y la ilusiones segadas de raíz. Y, sin embargo, una cosa son los sueños insatisfechos y otra bien distinta, como a ello se refirió Horkheimer —radicalizando el materialismo de Benjamin-, el mal causado, la injusticias padecidas y lo irreversible de la muerte.

\section{Salvar lo que carece de esperanza (entre religión, materialismo y justicia)}

En este sentido, en los Escritos de juventud, Lecciones y el libro de aforismo Ocaso de Horkheimer hay un sentido de la justicia vinculado, como ocurre de distinta manera en Benjamin, con la religión y el materialismo. En cuanto a la religión es para el frankfurtiano expresión primera del anhelo de justicia frente a la injusticia terrena, expresión de los deseos y esperanzas de felicidad truncados e incumplidos de las mayorías que quedaron en las cunetas de la historia, de las víctimas de la lógica de la dominación que, como denunciara junto a Adorno en Dialéctica de la Ilustración (1947), ha hecho de la historia de la emancipación y la libertad, una historia de injusticia, de sufrimiento y exclusión. Por tanto, la religión fue el lugar para la emancipación de lo que queda pendiente en términos de injusticia de las mayorías. La religión fue por eso, originalmente, un impulso subversivo, una protesta, un momento crítico para sociedad dominante. Para Juan J. Sánchez, este es el momento de verdad de la religión, pues es precisamente «el impulso religioso en cuanto inagotable anhelo de justicia universal el que hizo materialista a su pensamiento y al que, a su vez, dio a su materialismo su singular radicalidad» (Horkheimer, 2000: 15-17). Se da, pues, en Horkheimer un sentido de la justicia que emparenta estrechamente lo que en principio puede contraponerse, es decir, religión y materialismo. El proceso materialista de este impulso religioso primero acontece, entonces, cuando el pensamiento se asume en tanto praxis subversiva frente a las injusticias sociales dominantes y el sufrimiento que origina. Y llega a ser un materialismo radical en el proyecto teórico-práctico de una sociedad racional, de una sociedad justa, feliz, una sociedad que encontrara el cumplimiento de una justicia plena, el sueño de una historia del sufrimiento definitivamente reconciliada. Fue el horizonte de este singular cruce de caminos entre religión, materialismo y justicia donde el pensamiento de Horkheimer se encontró con el de Adorno y Benjamin. En una carta dirigida a Horkheimer en 1935, Adorno logró condensar el momento de verdad de este común cruce de intereses: salvar lo que carece de esperanza. Esa singular constelación y su momento de verdad será lo que preserve al pensamiento de caer en el consenso ideológico de los vencedores y la apertura de un horizonte de justicia plena.

La memoria se establece, pues, como resorte crítico que no se presupone en el reconocimiento de la posibilidad institucional, pues en sus artículos prefijados no sólo se diluye cualquier efecto crítico en el derecho, sino también sus pretensiones reales de una emancipación inconcebible desde la ideología de lo normativo. Porque para estos pensadores que levemente se han mencionado aquí, el padecimiento social no se deja reducir y comprender exclusivamente a partir de una teoría política de la justicia y su lenguaje basado en la asignación o privación de derechos. En efecto, esta crítica encuentra en las diversas experiencias de injusticia y sufrimiento no sólo un signo de la negatividad constitutiva de la forma de vida capitalista, sino también, en su propio marco de justificación teórica, 
un testimonio existencial de la necesidad histórica de una praxis emancipadora. Una existencia de sufrimiento histórico no debe ser sólo diagnosticada o denunciada, sino también, como conviene Adorno, ser asumida desde las propias categorías del pensamiento como expresión ella misma de la emancipación.

\section{Por una dialéctica de lo sensible o cómo visibilizar a los sin nombre}

En la obra ya citada con anterioridad, Qué hacemos por la memoria (2013) - y cuyo título completo aparece desplegado entre las líneas del propio título: para reparar a las víctimas, hacer justicia, acabar con la impunidad y por la construcción de la memoria histórica一, Rafael Escudero señala los problemas que tanto en la articulación de la ley así llamada de memoria histórica (Ley 52/2007), como en su ejecución, después de unos años desde su puesta en marcha, han impedido reafirmar, no sólo las políticas sobre hechos históricos importantes, sino su completa subordinación a derechos fundamentales, tales como «el reconocimiento de un derecho individual a la memoria personal y familiar de cada ciudadano» (Sauca Cano, 2008: 73). Esta aportación normativa, que resultaba novedosa respecto a documentos legislativos anteriores — que lo es en tanto que ampliación del derecho al honor y el derecho a la identidad y «a la propia biografía, al propio recuerdo» (Sauca Cano, 2008: 84-85)—, no obstante, quedaba en suspensión legislativa, según Escudero, en el abandono administrativo sufrido durante las últimas legislaturas del gobierno español - Partido Popular- y debido a la falta de apoyo financiero vía presupuestaria. Las partidas de los Presupuestos del Estado destinadas a la aplicación de la ley fueron tan pequeñas en el período que va desde 2009 hasta 2013, que en este último año queda eliminada la partida encargada de sufragar los gastos para las exhumaciones en fosas del franquismo y la consecuente responsabilidad pública sobre la identificación de cadáveres (Escudero, 2013: 43-45). La falta de voluntad política devuelve las miradas críticas acerca de una ley de memoria, que si bien no satisfacía - como vimos en los apartados anteriores- a un pensamiento crítico sobre qué debemos entender por memoria, al menos debía cumplir normativamente con la recuperación de cierta memoria histórica del pasado conflictivo de España durante la fase final de la Segunda República, la Guerra Civil y el franquismo, y, lo que es más difícil, la reconciliación de las partes implicadas en los actos de represión y violencia. Este gesto político revierte, sin duda, sobre un interés ideológico, o lo que es peor aún, en un intento de borrar del espacio público la proyección de un movimiento asociativo que, allá por el año 2000, consiguió ubicar en el centro del debate político sus reivindicaciones de justicia, verdad y recuperación de las víctimas del franquismo a través de los testimonios de los supervivientes, y de cuyos intereses la vigente Ley 52/2007 debía ser fiel reflejo. En este contexto, el pasado se convierte, en palabras de Escudero, en un «molesto enemigo ideológico para la derecha española» (2013: 45) y la memoria sobre esta en un relato que, en vez de presuponerse emancipador, se mide bajo la amenaza de la desestabilización social, política e ideológica de España. 
Así, ante el constante miedo de abrir viejas heridas, el actual panorama sobre aquel principio del pensamiento crítico de reconocer a través de la memoria lo frustrado por la historia violenta, empieza a tener distintas respuestas que pretenden trascender — por cierto, muy benjaminianamente- la inoperancia de la ley de memoria histórica. En ello tiene mucho que ver la más importante carencia de la Ley 52/2007 que, contradictoriamente, ante el derecho de dar a conocer nuestra historia, silencia lo que realmente ocurrió y que participa en la reivindicación legal de una distinción entre víctimas y victimarios o, como hemos venido esbozando a lo largo del artículo, entre vencedores y vencidos. Esta falta de reconocimiento sobre los vencidos ha llevado a señalar la memoria sobre la Guerra Civil española y el franquismo como un concepto discursivamente deficitario, si bien, como aludía Walter Benjamin, el honor de la víctima sólo podría ser restituido en el reconocimiento de su propia opresión, es decir, más allá de los hechos — que se pueden olvidar-, en el testimonio de cuya narración los acontecimientos son legados en forma de memoria, o dicho en términos del pensador berlinés, en el recuerdo de las injusticias sobre la acción política del pasado para una construcción fática de la historia. Y es que el reconocimiento de los hechos históricos, ya contempla una reparación histórica. Según Reyes Mate, la justicia benjaminiana consistiría, precisamente $-\mathrm{y}$ como ya se ha mencionado en alguna ocasión-, en hacer del mundo un bien común a partir de una reconstrucción de los sucesos históricos, para así visibilizar lo oculto de las sociedades en democracia: «esa visibilización de los sinnombre (tarea de la memoria) es el supuesto de una construcción justa» (Mate, 2011: 37).

Precisamente, en esa tarea de dar visión a los sin nombre, los últimos trabajos de Didi-Huberman dan un paso hacia adelante en la compleja cuestión sobre la memoria de los vencidos al vincular la cuestión de la memoria con los problemas de la representación - imagen —, que hasta el momento no había sido tratado con la debida exigencia. Con la máxima «los pueblos son hoy más visibles de lo que jamás lo han sido» (Didi-Huberman, 2013: 17), por un lado conecta directamente con las ideas benjaminianas sobre la memoria histórica como una solución política en imágenes democráticas ${ }^{9}$, pero sobre todo ahonda en la cuestiones que ya Huyssen abordara acerca de la peligrosidad de los media como memoria de la modernidad ${ }^{10}$. Sin embargo, las ideas de Huberman alcanzan momentos más problemáticos al añadir sobre lo anterior que a dicha mejora de la representación de los pueblos —que

\footnotetext{
9 Como indica Didi-Huberman en otro lugar, «la imagen no es un simple acontecimiento en el devenir histórico, ni un bloque de eternidad insensible en las condiciones de ese devenir» (2011: 143), sino una constitución dialéctica de la historia y en la historia misma. El movimiento dialéctico asociado a la imagen, por una parte, rompe con la idea asociada de la imagen como fijación e identificación con el objeto retratado, lo cual reduce la imagen a un documento accesorio de la historia. La imagen dialéctica [originariamente término acuñado y popularizado por Walter Benjamin: dialektiche Bild] supone, desde el momento de su presentación, una apertura hacia dimensiones temporales diacrónicas que nos señala, más allá de la conservación, una voluntad que conecta el pasado desde el presente.

${ }^{10}$ El debate abierto por Huyssen en torno a la relación entre medios de comunicación y memoria se basa en una supuesta y vieja contraposición crítica —-Benjamin contra Adorno- de la memoria frente a derivas reificadoras de la industria cultural. Si el teórico de la memoria alemán aporta algo sobre este debate, esta parte del uso desmedido en el que la cultura asume valores de la representación anamnética en términos de dramatización y espectacularización estéticas, sobre todo, de los sucesos alrededor del Holocausto judío (Huyssen, 2016: 391). Sin embargo, no entra Huyssen en aspectos más actuales y honestos sobre el uso de los nuevos medios de comunicación como herramientas críticas sobre la memoria en su aspecto más social y político. Para la cuestión de la memoria y la industria cultural conviene consultar El Holocausto y la cultura de masas, de Álvaro Lozano — consúltese en la bibliografía al final del artículo-.
} 
lo están gracias al auxilio que les proporcionan los media, según nos indica el pensador francés- se debe a la contribución de las victorias de la democracias. Sin embargo — y he aquí la paradoja - a mayor posibilidad de representación —que es estética y política a la vez- «los pueblos están expuestos a su desaparición» (Didi-Huberman, 2013: 18). La sobre-exposición a la que el teórico francés se refiere es, mediante su configuración en imágenes estereotipadas, a su permutación en espectáculo, o como afirman otros muchos teóricos contemporáneos en torno a la memoria, a su banalización y, por ende, convertida finalmente en una cuestión superficial destinada a ser olvidada.

Pensando entonces en el objeto fundamental de la vida pública y política contemporánea, que según Huberman sería esta exposición de los pueblos, deberíamos preguntarnos de qué pueblo se trata. Cuando el francés menciona pueblo, se refiere a esa tradición de oprimidos por los acontecimientos de la historia, que emocionalmente liga con esa idea benjaminiana acerca de la coincidencia de la crisis de la figuración con la crisis de las democracias, al reconocer también en estas - en su famoso trabajo La obra de arte en la época de su reproductibilidad técnica (1935)—, una crisis de las condiciones de exposición del hombre político. Frente a los vencedores de la historia - como añdiría aquí Walter Benjamin: aquellos que la escriben — son los vencidos los que Huberman señala como dispuestos para desaparecer, justamente por hallarse estos sobreexpuestos «en representaciones consensuadas de la historia» (Didi-Huberman, 2013: 30), es decir, los que discursivamente cuentan -e, incluso en otros casos, estéticamente- con una menor representación en lo predispuesto hegemónicamente en lo que se conoce como historia oficial. Entonces, ¿cómo poder hacer visible esa parte patética de la historia, de un pueblo, que está históricamente expuesto a su olvido? La solución de Didi-Huberman acompaña a la idea benjaminiana que promulga un principio constructivo - material - sobre los discursos de la modernidad que, por un lado restrinja el poder reificante de cualquier documento cultural, al tiempo que promueva una distinta disposición material que, como dice el pensador francés, no tiene nada que demostrar, sino que muestra y expone una imagen — documental— de la historia. Esto mismo habría sido propuesto por Benjamin desde las estéticas experimentales sobre la narrativa de una literatura moderna - Proust y Joyce- e, incluso, desde las nuevas incursiones formales en la edición cinematográfica - Vertov e Eisenstein - como modelo de montaje documental y en contra del documento informativo de carácter oficial en el cual lo ahora visible inaugura otra forma de mirarlos ${ }^{11}$. Se trata, pues al final, de una cuestión narrativa, o dicho de otro modo, de poder contar las cosas fuera de un régimen de representación discursiva lineal sobre la positivista disposición de los datos historiográficos. Es como si a esos vencidos de la historia les correspondiera una nueva forma de representación histórica a partir de otras formas del imaginario cultural fundamentado en una fenomenología de los cuerpos insignificantes de la propia historia que los conforma.

\footnotetext{
11 En un trabajo posterior, aunque deudor de su ensayo «Exponer a los sin nombre» (2013), Didi-Huberman se refiere a este gesto sensible como un «dialectizar lo visible», esto es, «fabricar otras imágenes, otros montajes, mirarlos de otra manera, introducir ahí la división y el movimiento asociados, la emoción y el pensamiento conjugados. En definitiva, frotarse los ojos: frotar la representación con el afecto, el ideal con lo reprimido, lo sublimado con lo sintomático» —cita extraída del artículo de Didi-Huberman titulado «Hacer sensible» y publicado en el monográfico ¿Qué es un pueblo?, Madrid, Ediciones Casus Belli, 2014-.
} 


\section{La narrativa transmedia como ejercicio de memoria histórica: el proyecto Vencidxs}

La solución de Didi-Huberman es también, sin duda, una resolución estético-política sobre las ideas de un Walter Benjamin que, como dijimos al comienzo de este artículo, parecía destinado a la indiferencia en su propio entramado filosófico. Al mismo tiempo, las propuestas del francés asimilan las teorizaciones sobre la memoria — crítica — benjaminiana y su distinción de un concepto de recuerdo devenido en texto jurídico para convertirlo en un ejercicio de memoria real y posible: visibilizar esa parte maldita de la historia y exponer las imágenes más negras de la historia de la humanidad. El sentido constructivo - y materialista - que va desde Benjamin, pasando por Reyes Mate y acabando por el propio Didi-Huberman, es una de las ideas fundamentales que podemos encontrar en Vencidxs, proyecto creado a partir de numerosas asociaciones y colectivos relacionados con la memoria histórica $^{12}$ y que, no obstante, rechazan la resolución de una ley como la de la memoria histórica española, pues en sus postulados se da lo que para estos colectivos suponen fórmulas conciliadoras — que en realidad son una «apuesta por el olvido y por la resignación que se han ido demostrando inútiles e hipócritas (Amar Sánchez, 2010: 74)»— entre los bandos enfrentados desde los tiempos de la Segunda República hasta el final del franquismo y no lo que es una cuestión más urgente: la distinción todavía tabú entre vencedores y vencidos. De ahí una de las máximas evidentemente benjaminianas del proyecto: el momento lo tenemos que crear nosotros. Mediante un trabajo sin subvenciones públicas y autogestionado — crowdfunding - por un equipo multidisciplinar, el proyecto audiovisual trata de recopilar los últimos testimonios de los supervivientes del conflicto civil español: milicianos, republicanos en el ejército franquista, gudaris, presos políticos y sociales, mujeres sometidas a humillaciones, detenidos y torturados, exiliados, brigadistas internacionales... Todos ellos identidades sujetas a la derrota y a las formas de supervivencia posteriores a conflicto violento ya en un estado democrático, en el que, empero, siguen desubicados entre el olvido, el duelo y la resistencia. La importancia de crear un entorno colaborativo en Vencidxs, lejos de ser un modelo de marketing vinculado a los productos transmedia, supone un gesto simbólico en el que el micromecenazgo, además de ayudar a financiar la producción del documental, propicia cierto sentido de pertenencia a una comunidad que, en oposición a los poderes institucionales (Castells, 2011: 133), «ha trabajado de forma asamblearia durante más de tres años, que ha conseguido los recursos económicos por cuenta propia y que ha implicado a más de cincuenta asociaciones y colectivos relacionados con la memoria histórica y la lucha social» ${ }^{13}$. Quizás sea esta la característica que define a Vencidxs como un proyecto transmedia, más próximo a la denuncia política y social, que a una mera justificación estética, precisamente por convertir el principio de visión expandida — como en el arte: multiplicar los puntos de vista (García Canclini, 2010: 24) — en una estrategia de distinción donde los medios de expresión,

\footnotetext{
12 Para una información más detallada del proyecto, acúdase a la dirección web http://vencidxs.com/es/el-proyectovencidxs/ (última consulta, 16-07-2017). Como ya indica el propio título del proyecto, con la sustitución de la letra $o$ por la $x$, sus responsables alteran simbólicamente el régimen de significación genérica y civil de estos vencidos — hombres y mujeres; desconocidos y olvidados - en la represión civil antes, durante y después de la guerra.

${ }^{13}$ Citado en el dossier informativo incluido en http://vencidxs.com/es/el-proyecto-vencidxs/ (última consulta, 16-072017).
} 
junto con la participación de colectivos sociales, intentan arrojar algo de luz sobre los relatos oficiales del pasado a través de un poder narrativo ${ }^{14}$ y que, así, se cumpla con ese imperativo de la memoria que a lo largo de este artículo hemos intentado escudriñar: «que la historia no se pierda, puesto que seguimos sin construir una verdadera memoria» ${ }^{15}$.

Aquí, la memoria histórica, en tanto que reconstrucción de los datos proporcionados por el presente y proyectados hacia un pasado oprimido aún por reinventar, y la memoria colectiva —entendida, con Maurice Halbwachs (2004), como una serie de recuerdos (una combinación de ideas, imágenes y conceptos) que remiten a la experiencia que una comunidad puede legar a un grupo de individuos - convergen, por tanto, en un mismo interés por la recuperación de aquella parte social oprimida durante el conflicto, los vencidos, en medio de una amnesia que también es colectiva. De este modo, la memoria, se realiza como una cuestión sensible para las sociedades que se constituyen dentro del marco democrático del Estado de derecho y, por tanto, asunto «que facilita una respuesta al desarrollo de movimientos tan desiguales y contradictorios como el que constituye los mal llamados indignados» (Roitman Rosenmann, 2012: 30). No es casualidad que las pretensiones reivindicativas de este proyecto coincidan en su totalidad con algunos de los planteamientos del 15-M. Si la responsabilidad en la construcción de memoria corresponde a alguien, como pretende el proyecto Vencidxs, esta debe de recaer en las generaciones venideras - estrategia política articulada dentro del programa reivindicativo durante las asambleas y concentraciones del 15-M-, una vez que estamos presenciando la desaparición de los últimos testigos directos (Roitman Rosenmann, 2012: 43). Vencidxs es, por eso, un proyecto que nace de ese momento de descontento político y lo convierte en un malestar social generalizado que coincide, además, con el incumplimiento del gobierno sobre la ejecución total de la Ley de memoria histórica. De ahí la necesidad de recuperar los espacios públicos para una refundación de la política o, como propone Castells de manera más pragmática, «reprogramar la política» (2012: 34) a través del activismo social. Sobre esta idea Vencidxs no funciona ya sólo como un ejercico de protesta política aislada, sino como un verdadero gesto de contrapoder, es decir, como un espacio de comunicación autónoma - donde compartir en comunidad el dolor y la esperanza sobre el pasado- fuera del control de gobiernos e instituciones que «a lo largo de la historia han monopolizado los canales de comunicación como cimiento de su poder» (Castells, 2012: 20). La necesidad del proyecto Vencidxs de ir más allá de la visibilización, tiene que ver, pues, con la teorización del sociólogo al entender los movimientos sociales como una necesidad política que, sin embargo, no deriva únicamente en una acción sobre el espacio urbano - lo que se manifiesta

\footnotetext{
14 Lina Srivastava (2014) introduce una muy interesante -y significativa - permutación de narrativas entre la potencialidad del power of narrative y la performatividad del narrative power cuando se trata de la producción una experiencia transmedial que, como en el caso del proyecto Vencidxs, suscribe cierto compromiso político con el objetivo de incentivar la acción de una comunidad o grupo. Esta idea parece engarzar con la propuesta teórica de Enzo Traverso (2007: 48) al discriminar el italiano entre memorias fuertes —oficiales- y débiles — subterráneas—, siendo estas últimas las que dependen de narrativas otras que otorguen una mayor visibilidad y reconocimiento de las injusticias ante los poderes públicos.

${ }^{15}$ Citado en el dossier informativo incluido en http://vencidxs.com/es/el-proyecto-vencidxs/ (última consulta, 16-072017).
} 
simbólicamente con la ocupación del espacio público-, sino con la creación de un espacio híbrido en el que las redes sociales de Internet y las nuevos formatos audiovisuales interactúan culturalmente como prácticas, más que transformadoras, emancipatorias «mediante la interrupción de las conexiones dominantes y las conexiones de resistencia y cambio social» (Castells, 2012: 26). Con el reciente trabajo de Anxo Abuín (2017) entendemos aquí que la transmedialidad de Vencidxs ha de ser entendida como un ejercicio de expresión política alternativa en los términos en los que Lina Srivastava (2014) entiende el Transmedia activism, esto es, como una estrategia transmedial que, lejos de establecerse en los paradigmas clásicos de la comunicación, trabaja sobre otros parámetros alrededor de la protesta y la crítica social: obtener impacto social, influir sobre las formas de percepción sobre el pasado conflictivo y construir una comunidad participativa en la construcción de otros relatos posibles.

Con estos presupuestos, el proyecto se articula en una significativa narrativa transmedia, que va de la desnuda voz del testimonio real sobre el pasado histórico al relato de voces e imágenes expandidas en las que este se convierte en su producción a través de cada uno de los medios y en los que las declaraciones, en primer lugar, son capturadas como archivo audiovisual - de carácter público, pero también destinado a la purga íntima- y, en un segundo momento, como ejercicio afectivo e intergeneracional, pues son los jóvenes - familiares o encausados por el tema- aquí los creadores de esa memoria audiovisual que ha de llegar al espectador. En ese sentido, no parece desencaminada Marianne Hirsch en lo que ella misma ha denominado postmemory, una idea actualizada de la memoria en la que, ya no sólo los supervivientes, sino las sociedades herederas de sus relatos traumáticos asumen la construcción —estética o no- del recuerdo histórico en democracia ${ }^{16}$.

Aunque Henry Jenkins establece las características de una nueva forma de narrativa expandida a través de los medios digitales, cuando afirma que «cada medio hace lo que hace mejor, a fin que una historia pueda ser introducida en una película, ser expandida para la televisión, novelas y $\mathrm{HQ}_{\text {» }}$ (Jenkins, 2008: 134), en su forma ideal de narración expandida sobre el discurso de la Historia —en contraposición de la Intra Story que también se plantea en Vencidxs: «El total de la cinta se compone, prácticamente, de la grabación de los testimonios, que no están identificados: la idea era dar vida a un personaje global. Los testimonios de todos ellos construyen un hilo histórico que empieza con la proclamación de la II República española y termina hoy, haciendo referencia a la eclosión de los movimientos sociales y a todos los jóvenes que son los que deben tomar el testigo»— la definición de Pratten, nos parece más adecuada para este proyecto, ya que transmedia storytelling «is telling a story across multiple media and preferably, although it doesn't always happen, with a degree of audience participation, interaction or collaboration. In transmedia storytelling, engagement with each successive

\footnotetext{
16 Postmemory es un término propuesto por la teórica de la memoria Marianne Hirsch en su ya conocido ensayo de 1992 titulado «Family Pictures: Maus, Mourning and Post-Memory», aunque hace unos años que ya ha desarrollado las principales ideas de este en un trabajo posterior, The Generation of Postmemory (2008). El concepto explica la relación existente entre las generaciones que siguen a los supervivientes y testigos de los acontecimientos traumáticos de la historia conflictiva. Estos eventos, según Hirsch, son recordados indirectamente a través de historias, imágenes u otros objetos familiares que reconstruyen a partir de la experiencia de la transmisión de los acontecimientos (2008:106-107); tal y como el propio Benjamin había problematizado en su trabajo «Experiencia y pobreza» (1933) acerca de la imposibilidad de dicha experiencia durante la modernidad.
} 
media heightens the audience's understanding of, enjoyment of and affection for the story» (Pratten, 2011: 1), sobre todo cuando dichos afectos participan de una experiencia de sufrimiento sobre los acontecimientos de la realidad histórica que nos constituye.

Así la articulación del proyecto a partir de la intersección entre los formatos tradicionales - la ya antigua tecnología del libro hecho con imágenes- y los nuevos formatos -el documental homónimo (Vencidxs) y la propia web-red - intenta cuestionar cómo se están configurando actualmente las identidades individuales y colectivas en relación con el pasado y la gestión de la memoria en sus distintos ámbitos de acción, ya sean estos sociales, políticos — memoria histórica- o personales. En este sentido, la función de los medios audiovisuales resulta determinante, sobre todo, como expone Garde-Hansen, en la manera en la que ahora usamos los media para construir memorias, pues el público «has been transformed into shifting and various roles as spectators, viewers, users, consumers, $[\ldots]$ and now digital creative who have the tools of media production at their disposal» dentro de lo que denominamos memoria colectiva (Garde-Hansen, 2011: 48), como hemos visto con anterioridad. De esta forma surge una narrativa que abandona las formas tradicionales en la que los media tratan - documentalmente- el tema de la memoria histórica, pues, como el propio proyecto reclama, este es «mucho más que un proyecto de memoria histórica, en el que son los propios protagonistas los que cuestionan la propia historia» ${ }^{17}$. Al mismo tiempo, se trata de la búsqueda de narrativas más democráticas, entendidas estas también como el lugar de una mejor representación social y política que hasta ahora había sido cubierta por el relato informativo en el periodismo o ciertas narrativas ficcionales (Scolari, 2012).

Una imagen lógica de representación que no necesariamente pasa por vía parlamentaria, sino que, en su objetivo de trascender la representación única — de la historia, de sus fechas y de sus personajes-, la narrativa transmedia de Vencidxs exige más visibilización en su distinta adecuación en cada uno de los medios que utiliza, sobre todo aquello que hasta ahora ha sido ocultado, para conocer de primera mano «la verdadera historia de nuestros pueblos» ${ }^{18}$. Por eso, en este proyecto el documental se instituye sobre la idea benjaminiana - luego rescatada por Didi-Huberman para la restitución de una relación crítica entre Benjamin y la técnica ${ }^{19}$ - de montaje documental -imagen en relación dialéctica con la palabra que conforman el testimonio- en tanto que ejercicio crítico ante la información histórica más oficial sobre la Guerra Civil española. Aquí, pues, se trata de dar posibilidad a los nuevos medios y, a su vez, a las nuevas formas de escritura documental, que más allá

\footnotetext{
17 Citado en el dossier informativo incluido en http://vencidxs.com/es/el-proyecto-vencidxs/ (última consulta, 16-072017).

18 Ibíd.

19 Hay que entender, por tanto, que la crítica de la técnica en Benjamin es también pensada dialécticamente como el proceder constructivo de la memoria —en el montaje, por ejemplo- y no sólo desde el romántico reproche sobre sus inconvenientes modernos. En este sentido, habría una doble lectura de la técnica que debe ser entendida a la sazón de la dicotomía entre vencedores y vencidos. El segundo sentido sobre la técnica es la que el pensador alemán otorga a los vencidos, en cuanto estos son capaces a partir de un nuevo uso, realizar un trabajo de reconstrucción — de memoriahistórica. Este es el sentido de la técnica como emancipación, es decir, la que es re-aprovechada con un fin crítico; frente a ella esa esa otra tecnología, la que está al servicio del progreso y la ciencia.
} 
de buscar una afección social y populista, quieren servir como verdadero relato histórico en el complicado trabajo del reconocimiento de las víctimas en democracia, precisamente, donde la ley de memoria histórica no alcanza a ver: las nuevas formas audiovisuales como medio para la exposición pública de los vencidos, la reivindicación de una conciencia histórica sobre el pasado y la construcción emancipada de una memoria crítica aún por realizar.

\section{Bibliografía}

ABuín, A. (2017): «Táctica frente a estrategia: transmedialidad y activismo en Ciutat Morta», Tropelías. Revista de Teoría de la Literatura y Literatura Comparada, 27, pp. 110-119; en https://papiro.unizar.es/ojs/index.php/tropelias/article/view/1543 (última consulta, 16-07-2017). AdORno, Th. W. (2008): Crítica de la cultura y sociedad I. Trad. Jorge Navarro. Madrid, Akal.

AMAR SÁnchez, Ana M. (2010): Instrucciones para la derrota. Narrativas éticas y políticas de perdedores. Barcelona, Anthropos.

BENJAMIN, Walter (2012): «Tesis sobre el concepto de historia», en Escritos políticos. Ed. Ana Useros y César Rendueles. Madrid, Abada.

BENSAÏD, Daniel (2010): Walter Benjamin, sentinelle messianique. À la gauche du posible. Paris, Les Prairies Ordinaries.

CASTElls, Manuel (2012): Redes de indignación y esperanza. Los movimientos sociales en la era de Internet. Madrid, Alianza.

DIDI-Huberman, Georges (2013): «Exponer a los sin nombre», en Juan BARJA y César RENDUELES, eds., Mundo escrito. 13 derivas desde Walter Benjamin. Madrid, Pensamiento.

(2014): «Hacer sensible», en Alan BADIOU et al., ¿Qué es el pueblo? Trad. Javier Bassas Vila. Madrid, Casus Belli.

De la GarZa, María Teresa (2002): Política de la memoria. Una mirada sobre Occidente desde el margen. Barcelona, Anthropos.

Escudero Alday, Rafael - CAMPElo, Patricia - Silva, Emilio (2013): ¿Qué hacemos por la memoria histórica? Madrid, Akal.

EsCudero AldAY, Rafael (2011): Diccionario de memoria histórica. Conceptos contra el olvido; Madrid, Los Libros de la Catarata.

FUKUYAMA, Francis (1992): The End of History and The Last Man, New York, Free Press, 2006.

GARCÍA CANCLINI, Néstor (2010): La sociedad sin relato. Antropología y estética de la inminencia. Buenos Aires, Katz.

GARDE-HANSEN, Joanne (2011): Media and Memory. Edinburgh, Edinburgh University Press.

GóMEZ, Vicente (2009): «La teoría crítica en España. Aspectos de una recepción», Constelaciones. Revista de Teoría Crítica, 1, pp. 3-35.

Halbwachs, Maurice (2004): La memoria colectiva. Trad. Inés Sancho-Arroyo. Zaragoza, Prensas Universitarias de Zaragoza. 
HIRSCH, Marianne (2008): The Generation of Postmemory. Writing and Visual Culture after the Holocaust. New York, Columbia University Press.

HuYsSEN, Andreas (2002): En busca del futuro perdido. Cultura y memoria en tiempos de globalización. Trad. Silvia Fehrmann. México, Fondo de Cultura Económica-Instituto Goethe.

_ (2003): «Present Pasts. Media, Politics, Amnesia», en Present Pasts. Urban Palimpsests ante Politics of memory. Stanford, Stanford University Press, pp. 11-29.

JAY, Martin (2011): La imaginación dialéctica. Historia de la Escuela de Frankfurt y el Instituto de Investigación social (1923-1950). Trad. Juan Carlos Curutchet. Madrid, Taurus.

JENkins, H. (2008): Convergence Culture. La cultura de la convergencia de los medios de comunicación. Trad. Pablo Hermida Lazcano. Barcelona, Paidós.

KoHAN, Martin (2013): «La inactualidad de Benjamin», en Juan BARJA y César RENDUELES, eds., Mundo escrito. 13 derivas desde Walter Benjamin. Madrid, Pensamiento.

LOZANO, Álvaro (2010): El Holocausto y la cultura de masas. Madrid, Melusina.

LÖWY, Michael (2010): Juifs hétérodoxes. Romantisme, messianisme, utopie. Paris, Éditions de l'Éclat.

MAte, Reyes - ZAmorA, José A. (2011): Justicia y memoria. Hacia una teoría de la justicia anamnética. Barcelona, Anthropos.

Mate, Reyes (1999): Por una cultura de la memoria. Barcelona, Antrhopos. (2003): Memoria de Auschwitz. Madrid, Trotta. (2008): La razón de los vencidos. Barcelona, Anthropos.

PRATTEN, R. (2015): Getting Started in Transmedia Storytelling. A practical Guide for Beginners, en http://www.tstoryteller.com/getting-started-in-transmedia-storytelling (última consulta, 16-072017).

Ricoeur, Paul, (2000): La mémoire, l'histoire, l'oubli. Paris, Seuil.

RoITMAn Rosenmann, Marcos (2012): Los indignados: el rescate de la política. Madrid, Akal.

SAUCA CANO, José María (2008): «El derecho ciudadano a la memoria histórica: concepto y contenido», en José Antonio Martín Pallín y Rafael Escudero AldAY, eds., Derecho y memoria histórica. Madrid, Trotta.

SCOLARI, C. S. (2012): «Más allá de la ficción: el documental transmedia», en https:// hipermediaciones.com/2012/05/09/mas-alla-de-la-ficcion-el-documental-transmedia/ (última consulta, 16-07-2017).

SEVILLA, Sergio (2010): «La recepción en España de la Teoría crítica». Daimon. Revista Internacional de Filosofía, 50, pp. 157-167.

SRIVASTAVA, Lina (2014): «The Opportunities of Narrative: Story-Based Impact», en http://archiv. recampaign.de/wp-content/uploads/2015/02/214227049-Prasentation-Srivastava-ReCampaign2014.pdf (última consulta, 16-07-2017).

Todorov, Tzvetan (2004): Les abus de la mémoire. Paris, Arléa. 
96 Tropelías. Revista de Teoría de la Literatura y Literatura Comparada, 28 (2017) Antonio Alías

Traverso, Enzo (2007): El pasado, instrucciones de uso. Historia, memoria, política. Trad. Almudena González de Cuenca. Barcelona, Marcial Pons.

VÁZQUEZ GARCÍA, Francisco (2009): La filosofía española: herederos y pretendientes: una lectura sociológica [1963-1990]. Madrid, Abada.

ZAMORA, José A. (2004): Theodor W. Adorno: pensar contra la barbarie. Madrid, Trotta. 